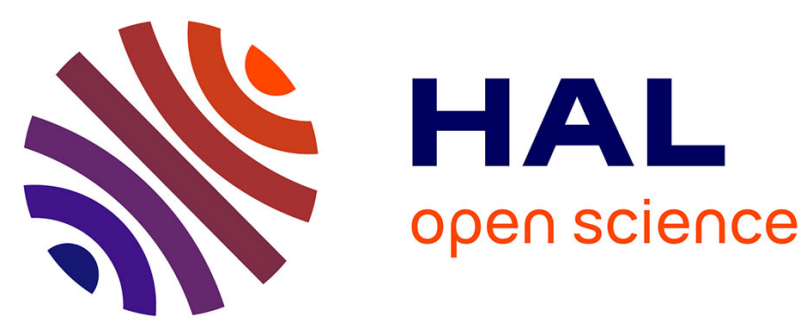

\title{
Electrostatic repulsion between HIV-1 capsid proteins modulates hexamer plasticity and in vitro assembly
}

Sonia Brun, Laurent Chaloin, Bernard Gay, Eric Bernard, Christian Devaux, Corinne Lionne, Nathalie Chazal, Laurence Briant

\section{To cite this version:}

Sonia Brun, Laurent Chaloin, Bernard Gay, Eric Bernard, Christian Devaux, et al.. Electrostatic repulsion between HIV-1 capsid proteins modulates hexamer plasticity and in vitro assembly. Proteins

- Structure, Function and Bioinformatics, 2010, 78 (9), pp.2144-2156. 10.1002/prot.22729 . hal02147175

\section{HAL Id: hal-02147175 \\ https://hal.science/hal-02147175}

Submitted on 7 Jun 2019

HAL is a multi-disciplinary open access archive for the deposit and dissemination of scientific research documents, whether they are published or not. The documents may come from teaching and research institutions in France or abroad, or from public or private research centers.
L'archive ouverte pluridisciplinaire HAL, est destinée au dépôt et à la diffusion de documents scientifiques de niveau recherche, publiés ou non, émanant des établissements d'enseignement et de recherche français ou étrangers, des laboratoires publics ou privés. 


\title{
Electrostatic repulsion between HIV-1 capsid proteins modulates hexamer plasticity and in vitro assembly
}

\author{
Sonia Brun, ${ }^{1,2,3}$ Laurent Chaloin, ${ }^{1,2,3}$ Bernard Gay, ${ }^{1,2,3}$ Eric Bernard, ${ }^{1,2,3}$ Christian Devaux, ${ }^{1,2,3}$ \\ Corinne Lionne, ${ }^{1,2,3}$ Nathalie Chazal, ${ }^{1,2,3}$ and Laurence Briant ${ }^{1,2,3 \star}$ \\ ${ }^{1}$ Centre d'études d'agents Pathogènes et Biotechnologies pour la Santé (CPBS), Université Montpellier 1, Montpellier, France \\ ${ }^{2}$ CNRS, UMR 5236, CPBS, F-34965 Montpellier, France \\ ${ }^{3}$ Université Montpellier 2, CPBS, F-34095 Montpellier, France
}

\begin{abstract}
Capsid protein (CA) is the major component of the human immunodeficiency virus type 1 (HIV-1) core. Three major phosphorylation sites have been identified at positions $S_{109}, S_{149}$ and $S_{178}$ in the amino-acid sequence of CA. Here, we investigated the possible consequences of phosphorylation at these sites on the CA hexamer organization and plasticity using in silico approaches. The biological relevance of molecular modeling was then evaluated by analyzing the in vitro assembly properties of bacterially expressed CA bearing $\mathrm{S}_{109} \mathrm{D}, \mathrm{S}_{149} \mathrm{D}$, or $\mathrm{S}_{178} \mathrm{D}$ substitutions that mimic constitutive phosphorylation at these sites. We found that a constitutive negative charge at position 109 or 149 impaired the capacity of mature CA to assemble in vitro. In vivo, HIV-1 mutants bearing the corresponding mutation showed dramatic alterations of core morphology. At the level of CA hexamer, $S_{149}$ phosphorylation generates inter-monomer repulsions, while phosphorylation at position 109 resulted in cleavage of important bonds required for preserving the stability of the edifice. Addition of a negative charge at position 178 allowed efficient assembly of CA into core-like structures in vitro and in vivo and significantly increased CA hexamer stability when modeled in silico. All mutant viruses studied lacked infectivity since they were unable to produce proviral DNA. Altogether our data indicate that negative charges, that mimic phosphorylation, modulate assembling capacity of CA and affect structural properties of CA hexamers and of HIV-1 cores. In the context of the assembled core, phosphorylation at these sites may be considered as an event interfering with core organization and HIV-1 replicative cycle.
\end{abstract}

Proteins 2010; 78:2144-2156.

(C) 2010 Wiley-Liss, Inc.

Key words: HIV-1; capsid; core assembly; electrostatic repulsion; phosphorylation.

\section{INTRODUCTION}

Structural proteins of human immunodeficiency virus type 1 (HIV-1) are encoded by the gag gene as a polyprotein Gag precursor. Following interaction of Gag with the plasma membrane, HIV-1 buds as a nascent immature particle. Inside the nascent virions, Gag polyproteins are radially organized and appear as electron-dense doughnut-shaped structures that are visible by electron microscopy. ${ }^{1}$ Concomitantly with particle release, Gag precursors are cleaved by the viral protease into processing intermediates that give rise to mature matrix protein (MA), capsid protein (CA), nucleocapsid protein (NC), and p6 protein, as well as two small spacer peptides, SP1 and SP2. When released, MA remains associated with the viral envelope, while a part of CA assembles into the viral core, and condenses into a cone-shaped structure present at the center of the mature virion. ${ }^{2}$ This morphological maturation of the retroviral particle is required for HIV-1 infectivity. The obvious function of the assembled CA is to package the viral NC-RNA complex. However, assembled CA certainly fulfils a more complex role with a tight regulatory function in early stage of virus replication between membrane fusion and nuclear import of the viral genome. Indeed, mutations in CA that alter core assembly or stability result in abortive infection and are frequently associated with impaired reverse transcription in target cells. ${ }^{3-6}$ Hence, early HIV-1 replication is highly dependent on appropriate assembly and stability of the viral core.

Additional Supporting Information may be found in the online version of this article Abbreviations: CA, capsid protein; CD, circular dichroism; CTD, C-terminal domain; CypA, cyclophilin A; HIV-1, human immunodeficiency virus type 1; MA, matrix protein; MHR, major homology region; NC, nucleocapsid protein; NTD, N-terminal domain; RT, reverse transcriptase; SIV, simian immunodeficiency virus; SP, spacer peptide.

Grant sponsor: GENCI-CINES; Grant number: 2009-075062; Grant sponsors: CNRS, ANRS and Sidaction

${ }^{*}$ Correspondence to: Laurence Briant, CNRS UMR5236, 4 Bd Henri IV, CS 69033, 34965 Montpellier cedex 2, France. E-mail: laurence.briant@cpbs.cnrs.fr

Received 30 November 2009; Revised 12 March 2010; Accepted 17 March 2010 Published online 23 March 2010 in Wiley InterScience (www.interscience.wiley.com). DOI: $10.1002 /$ prot.22729 
Particle assembly is driven by multiple cooperative contacts between adjacent Gag polyproteins. In the immature particle, the contacts of the Gag-Gag lattice are essentially mediated by the CA domain, the SP1 adjacent peptide and the NC region. ${ }^{5,7-9}$ After protease processing, the mature CA protein is released as a 231 amino-acids polypeptide that folds into two distinct globular domains linked by a flexible linker structured as a $3_{10}$ helix. ${ }^{10}$ The $\mathrm{N}$-terminal domain (NTD) (residues 1-145) consists of seven $\alpha$-helices. ${ }^{11,12}$ In mature CA, the amino-terminus refolds into a $\beta$-hairpin structure stabilized by the formation of a salt bridge that favors the formation of the mature core. ${ }^{13}$ The NTD moiety also contains an exposed proline-rich loop that regulates the recruitment to the viral particle of the host cell encoded peptidyl-prolyl-isomerase cyclophilin A (CypA). ${ }^{12,14}$ The C-terminal domain (CTD) (residues 151-231) is composed of four $\alpha$-helices, connected by short loops or turn-like structures. ${ }^{15}$ According to crystal structures and cryo-electron microscopy reconstructions, mature CA assembles into a lattice of hexagonal rings. ${ }^{16,17}$ The contribution of subdomains as well as functional residues in the full-length CA required for assembly and infectivity have been widely addressed using mutational studies. ${ }^{5,16}$ Informative observations have also been provided by in vitro assembly reactions based on the property of recombinant CA to polymerize spontaneously in solution, leading to the formation of cylindrical and conical shells similar in shape and size to viral cores when observed in electron microscopy preparations. ${ }^{16,18-21}$ Taken together, these data showed that the most prominent interface for CA dimerization lies in $\alpha$-helix 9 and the preceding loop (residues 174-189) in CA CTD.5,13,15 Very recently, an additional interface for CTD trimerization was identified from a pseudoatomic model of CA tubes that involves contacts between $\alpha$-helices 10 and $11 .^{22}$ Alpha helices 1,2, and 3, including residues 17-43, were also found critical for contact with adjacent NTD allowing hexamerization of CA. ${ }^{23}$ Additional contacts occurring between helix 4 in the NTD and helices 8 and 9 in the CTD of an adjacent CA monomer stabilize hexameric rings into a continuous lattice. ${ }^{23,24}$ Finally, the entire CA CTD displays a high flexibility 25 that allows the formation of swapped domains that involve the major homology region (MHR) and the $\alpha$-helix $6 .^{26}$

In solution, polymerization of recombinant $\mathrm{CA}$ into capsid-like structures requires molar concentrations of $\mathrm{NaCl}$ which suggests that neutralization of charge repulsion is required for CA assembly. ${ }^{16,18-21}$ Charge repulsion is frequently observed between subunits of CAs from a panel of viruses and has been proposed as a general mechanism that regulates virion assembly and stability. ${ }^{27-29}$ Considering HIV-1, the potential role of electrostatic charges in the CA assembly is suggested by the behavior of recombinant CA mutated at charged residues located in the $\mathrm{NTD}^{30}$ or $\mathrm{CTD}^{31}$ moieties, for which in vitro assembling capacities are increased. As an example, mutation of $\mathrm{E}_{180}$ residue into an alanine, truncating negatively charged side chains at the C-terminus end of the protein, stimulates CA assembly in solution. ${ }^{32}$ Analyzing charged residues clustered at the NTD of CA, nearby the intersubunit binding site, substitution of $\mathrm{E}_{45}$ residue by a neutral alanine or a charged lysine, had opposite effects on the kinetics of in vitro assembly. ${ }^{30}$ In vivo, viruses bearing the corresponding $\mathrm{E}_{45} \mathrm{~A}$ mutation displayed more stable cores and were found less infectious than the parental viruses. ${ }^{4,5,21}$ Accordingly, electrostatic repulsion has a significant effect on HIV-1 core assembly and stability.

HIV-1 CA exists in several phosphorylated isoforms during the course of infection. 33,34 During the past few years, we and others reported that virion-associated kinases, namely the cAMP-dependent protein kinase $\mathrm{e}^{35}$ and an unidentified $53 \mathrm{kDa}$ virus-associated kinase, ${ }^{36}$ are involved in CA phosphorylation. A systematic mutational analysis has identified $S_{109}, S_{149}$, and $S_{178}$ residues, located in the NTD, the interdomain linker and the CTD of CA respectively, as major phospho-acceptor sites. ${ }^{37}$ The precise function of CA phosphorylation remained unexplored until recently. Indeed, we reported that the conservation of these amino-acids residues is essential for viral infectivity as alanine substitution at each site inhibits proviral DNA synthesis. ${ }^{38}$ Moreover, each alanine replacement resulted either in aberrant CA assembly or impairment of assembled core stability. According to these data, the possible contribution of negative charges generated by CA post-translational modifications in the regulation of the assembly/uncoating process needs to be evaluated.

The purpose of the present study was to examine the effect of phosphorylation of CA in HIV-1 core assembly. Molecular dynamics simulations were conducted to evaluate the effect of phosphorylation at positions $S_{109}, S_{149}$, or $S_{178}$ of the hexameric model structure of CA. Data obtained from simulations were then reinvestigated using in vitro assembly experiments of bacterially expressed CA bearing an aspartic acid at each of these positions to mimic the constitutive presence of an electrostatic charge. Finally, $S_{109} D, S_{149} D$, and $S_{178}$ D HIV-1 viruses were generated. Based on biochemical approaches, the consequence on assembly of the viral core was investigated using electron microscopy. Our main result indicates that phosphorylation affects structural properties of hexameric CA in silico and modulates assembly of CA into corelike structures both in vitro and in vivo. These results help to understand the regulatory function of CA phosphorylation in HIV-1 life cycle.

\section{METHODS}

Molecular modeling and energy minimization of the hexameric form of HIV-1 CA

The CA crystal structure from Berthet-Colominas et al. ${ }^{24}$ was used for the hexamer construction (pdb 
code: 1E6J) and the modeling was achieved by taking into account crystal coordinates and electron density maps. ${ }^{17}$ The CA hexameric structure model was built using the Insight II biopolymer module (Accelrys, San Diego, CA). The mean criteria were that the internal/ external diameters of the hexameric ring were fixed to $25 \AA$ and $100 \AA$, respectively and that the orientation of the helices 1 and 2 lining in the inner hole were defined as distance restraints during short dynamics and minimization steps. Briefly, three distance restraints were defined between opposite chains of the hexamer by selecting the $\mathrm{C}$ atom of $\mathrm{A}_{92}$ residue (NTD) with a distance of $100 \AA$. Additionally, three constraints were applied between $\mathrm{N}_{21}$ and $\mathrm{S}_{41}$ (C atom) residues from opposite chain with a distance of $40 \AA$ to obtain $25 \AA$ of internal diameter for the all-atom system. $\mathrm{N}_{21}$ and $\mathrm{S}_{41}$ residues were selected because they belong to $\alpha$-helix 1 and $\alpha$-helix 2, respectively which allowed us to force the orientation of these helices to the inner part of the hexamer. Hexameric CA models were then immersed in a water box using Visual Molecular Dynamics (VMD) solvate and ionize modules and they were replicated by periodic boundary conditions. CA hexamers were subjected to 20 ps dynamics under the above mentioned constraints and energy minimized with Scalable Molecular Dynamics Software (NAMD) $2.6 \mathrm{bl}^{39}$ using the allatom CHARMM27 (Chemistry at HARvard Molecular Mechanics) parameter set for proteins 40 and the TIP3P model for all water in the system ${ }^{41}$ with 50,000 steps of conjugate gradient algorithm until a mean energy gradient of $0.001 \mathrm{kcal} / \AA$ is reached. Distance constraints were introduced with the Tool Command Language (Tcl) scripting interface implemented in NAMD by applying forces to selected residues. For energy calculations a dielectric constant of 1 was taken. The particle mesh Ewald method was used to calculate the full electrostatic interactions with a grid spacing of $1 \AA$ or less and order of six. Van der Waals interactions were reduced to zero by truncating between $10.0 \AA$ and $12.0 \AA$ with a switching function. The surface accessibility of serine residues 109,149 , and 178 was assessed after energy minimization by using the van der Waals representation and the Connolly algorithm.

Molecular dynamics simulations of CA hexamers were performed with NAMD with an integration step of $1 \mathrm{fs}$. The temperature was kept constant at $300 \mathrm{~K}$ by using Langevin dynamics for all non hydrogen atoms. Prior dynamics each hexameric system was subjected to 50,000 steps of conjugate gradient without any constraint and then heated gradually to $300 \mathrm{~K}$ with a temperature increment of $10 \mathrm{~K}$ after each 1000 steps. A 50 ps constant temperature equilibration was carried out followed by a 250 ps constant pressure and temperature equilibration using the Nosé-Hoover method. ${ }^{42,43}$ Production runs in NPT ensemble were performed for 5 ns and the coordinates of the trajectories were recorded every 1 ps. The
VMD software ${ }^{44}$ was used to analyze the simulation trajectories and to prepare the figures.

\section{Plasmids}

The pNL4.3 HIV-1 molcular clone and the pWISP9895 were obtained through the AIDS Research and Reference Reagent Program, Division of AIDS, NIAID, NIH. pNL4.3 S109D, pNL4.3 $_{\text {S149D }}$, and pNL4.3 $3_{\text {S178D }}$ molecular clones had been generated by site directed mutagenesis using the QuikChange II Site-Directed Mutagenesis kit (Stratagene) and the following oligonucleotides $\mathrm{S}_{109} \mathrm{D}-\mathrm{S}$ GACATAGCAGGAACTACTGATACCCTTCAGGAACAAA TAG, S $_{149}$ D-S GTAAGAATGTATAGCCCTACCGACATTC TGGACATAAGACAAG， S $_{178}$ D-S CTAAGAGCCGAGCAA GCTGACCAAGAGGTAAAAAATTGGATGA. S ${ }_{109} A-S$ GA CATAGCAGGAACTACTGCTACCCTTCAGGAACAAATAG, $\mathrm{S}_{149}$ A-S GTAAGAATGTATAGCCCTACCGCCATTCTGGAC ATAAGACAAG, S $_{178}$ A-S CTAAGAGCCGAGCAAGCTGCA CAAGAGGTAAAAAATTGG.

A similar approach was used to generate expression vector for recombinant CA using the pWISP98-85 plasmid as a matrix.

\section{Protein expression and purification}

Recombinant CA was purified from Escherichia coli BL21 cells transformed with the pWISP93-85 or derived mutants. Protein expression was induced for $3 \mathrm{~h}$ at $30^{\circ} \mathrm{C}$ with $400 \mu M$ Isopropyl $\beta$-D-1-thiogalactopyranoside (IPTG). Bacteria were collected, lysed by lysozyme $(0.1$ $\mathrm{mg} / \mathrm{mL}$ ) in $25 \mathrm{mM}$ Tris- $\mathrm{HCl}$ ( $\mathrm{pH}$ 6.5), $1 \mathrm{mM}$ phenylmethylsulfonyl fluoride (PMSF) and sonicated at $4^{\circ} \mathrm{C}$. Debris were removed by ultracentrifugation $70 \mathrm{~min}$ at $115,000 \mathrm{~g}$ at $4^{\circ} \mathrm{C}$ and CA protein was precipitated from the supernatant with $20 \%$ ammonium sulfate. Recombinant proteins resuspended in $25 \mathrm{mM}$ Tris- $\mathrm{HCl}(\mathrm{pH}$ 6.5) were dialyzed overnight at $4^{\circ} \mathrm{C}$ against $25 \mathrm{mM}$ Tris- $\mathrm{HCl}$ ( $\mathrm{pH}$ 6.5). CA was finally purified by mean of an ionexchange Hitrap QFF column using an $̈$ ATA fast performance liquid chromatography purifier (GE Healthcare). Elution was performed in $25 \mathrm{mM}$ Tris- $\mathrm{HCl}(\mathrm{pH}$ 6.5) with a linear gradient of $\mathrm{NaCl}$ at a flow rate of $1 \mathrm{~mL} / \mathrm{min}$. Concentration of CA samples was determined by absorbance at $280 \mathrm{~nm}\left(\epsilon=32,530 M^{-1} \mathrm{~cm}^{-1}\right)$. Purified protein solutions were stored frozen at $-80^{\circ} \mathrm{C}$ in $25 \mathrm{mM}$ Tris$\mathrm{HCl}$ ( $\mathrm{pH}$ 6.5), 10\% glycerol. Circular dichroism (CD) spectra of protein samples $(10 \mu M)$ were recorded on a Chirascan spectrophotometer (Applied Photophysics) at $25^{\circ} \mathrm{C}$ in $50 \mathrm{mM} \mathrm{Na}_{2} \mathrm{HPO}_{4}(\mathrm{pH} \mathrm{8.0)}$ at a scan speed of $20 \mathrm{~nm} / \mathrm{min}$ using quartz cells with $1-\mathrm{mm}$ path width.

\section{In vitro CA assembly and spectroscopic measurements}

Purified WT and mutant CA proteins were resuspended in $25 \mathrm{mM}$ Tris- $\mathrm{HCl}(\mathrm{pH} 8), 3.4 \mathrm{M} \mathrm{NaCl}$ to yield 
a 2.25 $M$ final salt and $40 \mu M$ protein concentration. The time course of the reaction was monitored at $25^{\circ} \mathrm{C}$ by measuring the turbidity at $350 \mathrm{~nm}$ on a UV-MC ${ }^{2}$ spectrophotometer in a $1-\mathrm{cm}$ path width quartz cuvette (Safas). Association rates were calculated by fitting the experimental kinetic data with a single exponential equation using the Grafit program (Erithacus software).

\section{Viral production and isolation of envelope-stripped cores}

Viruses were produced by transfection of 293T cells with HIV-1 molcular clones using the JetPei transfection reagent (QBiogen). Two days after transfection, viruscontaining supernatants were collected, filtered onto 0.22 $\mu \mathrm{m}$ membranes, aliquoted and stored at $-80^{\circ} \mathrm{C}$. Reverse transcriptase (RT) activity was measured as previously reported. 38 Viral cores were purified by a spin-through technique. Briefly, cell free virions were loaded onto the top of a discontinuous sucrose density gradient composed of $1 \mathrm{~mL} \mathrm{30 \%} \mathrm{sucrose} \mathrm{at} \mathrm{the} \mathrm{bottom} \mathrm{covered} \mathrm{by}$ $1 \mathrm{~mL}$ Triton $0.1 \%$ in $10 \%$ sucrose and centrifuged at $115,000 \mathrm{~g}$ in a SW32.1 Ti rotor (Beckman) for $4 \mathrm{~h}$ at $4{ }^{\circ} \mathrm{C}$. Cores were then resuspended in PBS and processed for negative staining.

\section{Electron Microscopy analysis}

For negative staining, isolated HIV-1 cores $(20 \mu \mathrm{L})$ were applied to Formvar-coated grids (mesh size, 200) and stained with $2 \%$ uranyl acetate for $1 \mathrm{~min}$. Preparations were examined with a Hitachi H.7100 transmission electron microscope.

\section{PCR analysis of viral DNA in infected cells}

Total DNA was extracted from MAGIC-5B cells $(8 \times$ 104) infected for $24 \mathrm{~h}$ with normalized amounts of DNAse-treated virus. The presence of contaminating pNL4.3 plasmid DNA was checked as previously described. ${ }^{37}$ HIV-1 DNA synthesis was then monitored by qPCR as follows: $100 \mathrm{ng}$ total DNA sample were added to the reaction mix containing $0.4 \mu M$ of each primer, and $2 \mu \mathrm{L}$ SYBR Green master amplification mix (Fast start DNA Master plus SYBR Green I amplification kit, Roche). For each amplification, a control reaction was performed in which DNA sample was replaced by water. Reactions were subjected to a first cycle of $10 \mathrm{~min}$ at $95^{\circ} \mathrm{C}$ followed by 40 amplification cycles of $15 \mathrm{~s}$ at $95^{\circ} \mathrm{C} ; 15 \mathrm{~s}$ at $65^{\circ} \mathrm{C}$ and $20 \mathrm{~s}$ at $72^{\circ} \mathrm{C}$ on the RotorGene system (Labgene). Fluorescence signal was recorded at the end of each cycle. A standard curve was generated from 10 to 100,000 copies of pNL4.3 plasmid. The copy numbers of HIV-1 DNA were normalized to that of the GAPDH DNA quantified in parallel as endogenous control. Primers used for amplification were: early DNA: 5'-AAGCAGTGGGTTCCCTAGTTAG- $3^{\prime}$ and $5^{\prime}$-GGTCTC
TCTGGTTAGACCA-3'; late DNA 5'-AGCAGCTGCTTTT TGCCTGTACT- $3^{\prime}$ and $5^{\prime}$-CCTGCGTCGAGAGAGCTCCT CTGG-3'.

\section{RESULTS}

Modeling the CA hexamer and impact of phosphorylation on structural behavior of CA hexamer

We modeled the impact of phosphorylation at positions $S_{109}, S_{149}$, and $S_{178}$ in CA [see Supporting Information Fig. 1(A)] on assembly capacities. This modeling was achieved using the crystal structure of HIV-1 CA 24 and by taking into account the electron density maps ${ }^{17}$ for the positioning of each monomer. From electron cryo-micrographs and image reconstruction, the internal/ external diameter of the hexameric ring was estimated to $25 \AA$ and $100 \AA$, respectively. Helices 1 and 2 were oriented facing the inner hole of the ring by using distance constraints included in the minimization step. The hexameric model structure appeared to be very similar to that observed by Li et al. ${ }^{17}$ In contrast with other published hexamer models, ${ }^{22,45}$ our hexamer model is less compact [Fig. 1(A) and Supporting Information Fig. $1(B)]$. The presence of one mutation may explain the different assembly properties observed between the $\mathrm{R}_{18} \mathrm{~L}$ mutant $^{22}$ and the WT CA in our present study. With the recently published CA hexameric structures ${ }^{45}$ which were obtained experimentally from crystal proteins, such differences may be related to the presence of either four mutations $\left(\mathrm{A}_{14} \mathrm{C} / \mathrm{E}_{45} \mathrm{C} / \mathrm{W}_{184} \mathrm{~A} / \mathrm{M}_{185} \mathrm{~A}\right)$ or to a template protein (CcmK4) fused to $\mathrm{CA}$, known to form spontaneously hexamer. Hexamers used in the present study were modeled using WT CA. Especially, when compared to the template-based or cross-linked CA crystal structures [Fig. 1(A) and Supporting Information Fig. 1(B)], it appears clearly that the internal diameter is smaller for the crystal structures and their CTD more tilted. This may be due to the presence of disulfide bridges created by the cysteine residues at the level of the fused protein. One important feature is the bending angle between NTD and CTD that is more closed for crystal structure compared to the model. CTD is known to be very flexible, ${ }^{25}$ a flexibility that allows CA hexamer to afford several packing geometries. This difference may also be explained by the use of the non tilted crystal structure of CA monomer (1E6J) during the modeling of our hexamer.

Concerning the phosphorylation sites, we found that all three serine residues presented a hydroxyl group that is largely accessible, especially $S_{109}$ as supported by the molecular surface or Connolly surface computation [Supporting Information Fig. 1(E)]. Molecular dynamics simulations were performed on hexameric CA assembly on a timescale of 5 ns. As previously reported, ${ }^{25}$ the CTD part of any CA hexamer tested was found to be more flexible than the N-terminal moiety and high amplitude 

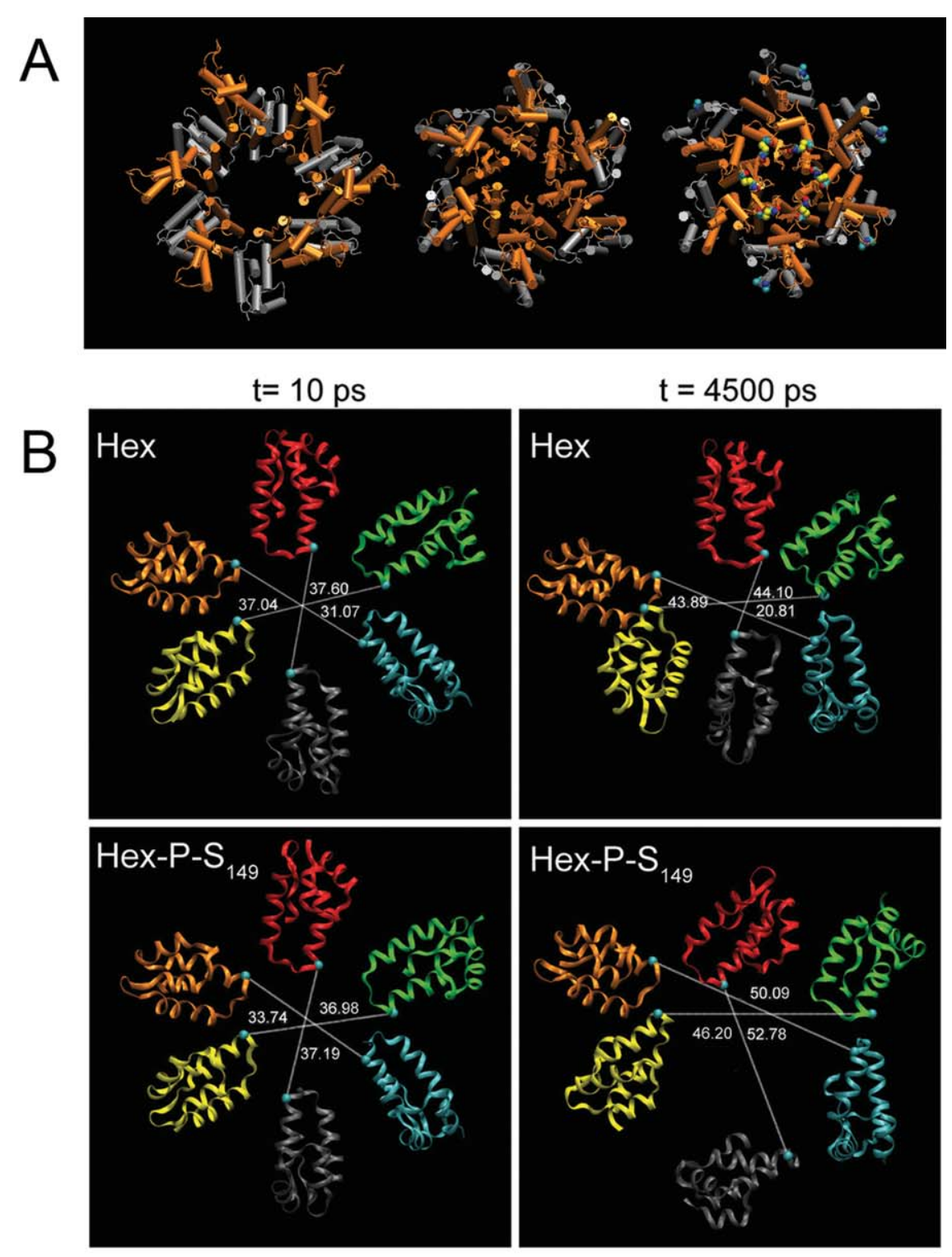

C

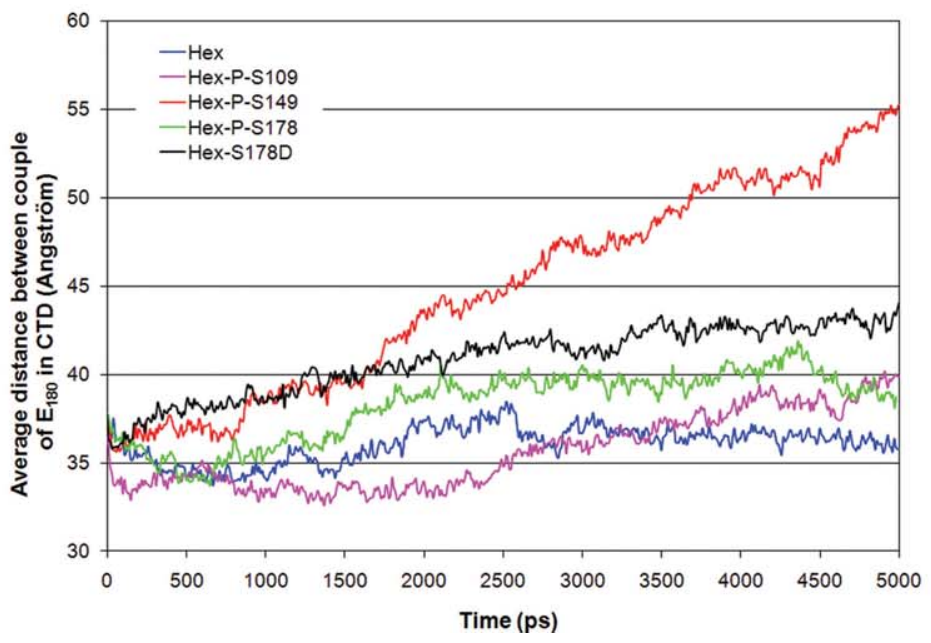

\section{Figure 1}

Molecular dynamics simulations of unphosphorylated and phosphorylated CA hexamers. (A) Cartoon representation of the CA hexamer model used in this study (left) and the two CA crystal structures recently solved, 3H4E (middle) and 3GV2 (right). NTD is colored in orange and CTD in gray and van der Waals atoms correspond to cysteine residues that were mutated in the CA construct. (B) Changes observed in the internal diameter of the CTD of the nonphosphorylated (top) and $\mathrm{S}_{149}$-phosphorylated CA hexamer (bottom) at the beginning (10 ps) (left panels) and at the end of the simulation (4500 ps) (right panels). For clarity, only the CTD is represented in ribbons and one color is assigned per monomer. Distances between two opposite monomers (distance inter- $\mathrm{E}_{180} \alpha$-carbon atoms) are indicated in $\AA$. (C) Fluctuations observed in the CTD of CA hexamers during dynamics simulation for unphosphorylated (Hex) and phosphorylated forms $\left(\mathrm{Hex}-\mathrm{P}-\mathrm{S}_{109}, \mathrm{Hex}-\mathrm{P}-\mathrm{S}_{149}\right.$, and Hex-P-S 178 ).

Fluctuations were measured from the average distances between two opposite $\mathrm{E}_{180}$ residues as for panel (A). As a control, $\mathrm{S}_{178} \mathrm{D}$ mutant (black line) is shown for comparison with Hex-P-S 178 . For clarity the standard deviation was not included. 
motions were observed during the simulation in this region. As illustrated in Figure 1(B), a partial closure of the CTD ring was detected for the unphosphorylated hexamers. However, this motion is generally paired with the extension of two neighboring monomers suggesting the existence of a compensatory effect. The average distances measured between two $\mathrm{E}_{180}$ residues from opposite monomers was used to determine this large collective motion of CTD as shown in Figure 1(C). This residue was selected because all $\mathrm{E}_{180}$ pairs (from two opposite monomers) are facing each other in the CTD moiety. When averaging the three inter-monomer distances for unphosphorylated CA hexamers, the final value appeared to be constant at about $35 \AA$. This result was also confirmed by measuring the circumference of the intra-hexameric CTD ring (data not shown). In contrast, when analyzing the CTD motions of the $\mathrm{S}_{149}$-phosphorylated $\mathrm{CA}$ hexamers, the inter-monomer distances were found to be increased upon simulation [Fig. $1(B, C)]$, indicating that phosphorylation at position $\mathrm{S}_{149}$ directly alters the structure of the hexameric ring or increases its flexibility. Overall, similar overtime fluctuations of CTD moieties were recorded for hexameric forms of unphosphorylated CA or CA phosphorylated on residue $\mathrm{S}_{109}$ or $\mathrm{S}_{178}$ [Fig. $1(\mathrm{C})$ ]. Looking into the details of the fluctuations, it is noteworthy that phosphorylation at $S_{178}$ position rendered the structure of the hexamers more stable with an average distance highly constant from 2 to 5 ns (about $40 \AA$ ). This stability of the CTD is explained by the three independent inter-monomers distances that kept constant during this period of time without any compensatory effect. Interestingly, the number of contacts (either intraor inter-monomer) was increased during the simulation compared to other CA hexamers with four additional salt bridges measured (between residues $\mathrm{E}_{28}$ and $\mathrm{R}_{154}$ or $\mathrm{K}_{25}$ and $\mathrm{D}_{152}$ for instance). As a control, the same simulation was achieved with $\mathrm{S}_{178} \mathrm{D}$ mutant instead of $\mathrm{S}_{178}$ phosphorylated CA hexamers and similar structural behavior was observed with rigorously identical interactions as those observed with $\mathrm{S}_{178}$ phosphorylated CA hexamers. This result indicates that a $S_{178} \mathrm{D}$ mutant may be an informative tool to investigate the consequences of CA phosphorylation using biochemical approaches.

According to the location of $\mathrm{S}_{109}$ residue, the large accessibility of its hydroxyl group and considering the role of this particular domain both in CA lattice formation and its location near the CypA-binding domain, the effect of phosphorylation at this position on NTD flexibility was further investigated. The hydroxyl group of $\mathrm{S}_{109}$ together with $\mathrm{Q}_{114}$ forms a hydrogen bond that stabilizes $\alpha$ helices 5 and 6 . Moreover, a salt bridge formed by two other residues, $\mathrm{E}_{113}$ and $\mathrm{R}_{97}$ reinforces the stability of this region [Fig. 2(A, B)]. All along the simulation, both interactions are preserved for unphosphorylated CA while they got lost with $\mathrm{S}_{109}$-phosphorylated CA. With unphosphorylated $\mathrm{CA}$, the distance separating $\mathrm{E}_{113}$ and
$\mathrm{R}_{97}$ was $3.90 \AA$ at the beginning of the simulation and $2.67 \AA$ at the end (5 ns). In contrast, with $S_{109}$-phosphorylated $\mathrm{CA}$, the distances were 3.20 and $10.59 \AA$ respectively [Fig. 2(C-E)]. Thus, the presence of a phosphorylation at position 109 perturbed the local tertiary structure of the hexamer by breaking important bonds that seem to be required for preserving the stability of the edifice.

\section{Modulation of in vitro CA assembly by negatively charged aspartic acid residues at positions 109, 149, or 178}

To evaluate the impact of negative charges at positions 109,149 , and 178 on CA assembly, we took advantage of the property of bacterially expressed recombinant CA to polymerize in vitro when incubated in the presence of elevated salt concentrations and to produce tubular polymers that accurately mimic mature capsid properties. 20 The size and charge of the carboxylic side chain of an aspartate residue are such that they can be used to mimic constitutive phosphorylation. Accordingly, phosphorylation of bacterially expressed CA was mimicked replacing $S_{109}, S_{149}$, or $S_{178}$ residues by a negatively charged aspartic acid, by site directed mutagenesis approach using the pWISP98-85 plasmid as backbone. After purification, structure integrity and folding of mutant CA proteins were found to be very similar to that of WT CA as observed from CD spectra [Fig. 3(A)]. The ability of recombinant $\mathrm{CA}$ subunits to assemble was then analyzed by following the increase in turbidity of a reaction mixture containing $40 \mu \mathrm{M}$ CAs resuspended in a high salt buffer [Fig. 3(B)]. In our experimental conditions, in vitro assembly kinetics were somewhat faster for $\mathrm{S}_{178} \mathrm{D}$ CA than WT, with association rate constants $8.4 \times 10^{-4} \mathrm{~s}^{-1}$ and $2.7 \times 10^{-4} \mathrm{~s}^{-1}$, respectively. When the final product was observed by electron microscopy [Fig. 3(C)], fibers of variable length corresponding to $\mathrm{CA}$ cylinder were observed for both preparations after a 180 min incubation period. Thus, CA assembles in vitro independently of the charge of residue present at position 178. Upon analysis of $\mathrm{S}_{149} \mathrm{D} \mathrm{CA}$, we found that this mutant formed correctly folded tubes with a similar rate of assembly to that of WT CA (rate constant of $3.5 \times 10^{-4} \mathrm{~s}^{-1}$ and $2.7 \times 10^{-4} \mathrm{~s}^{-1}$, respectively). Interestingly $\mathrm{S}_{149} \mathrm{D} \mathrm{CA}$ showed a significant lag, presumably a manifestation of the slow formation of an assembly intermediate that precedes the tubular structures organization. Moreover, the maximum turbidity observed from this reaction remained significantly lower than that observed with WT CA [Fig. 3(B)], meaning either that less tubes are produced or that products formed in vitro by $\mathrm{S}_{149} \mathrm{D}$ CA are lower in size than those generated by WT CA. This suggests that the critical concentration required for $\mathrm{CA}$ polymerization is higher when $S_{149}$ residue is mutated. This result is consistent with electron microscopy imaging of the final reaction products [Fig. $3(\mathrm{C})$ ]. Finally, $\mathrm{S}_{109} \mathrm{D}$ substitution was found 

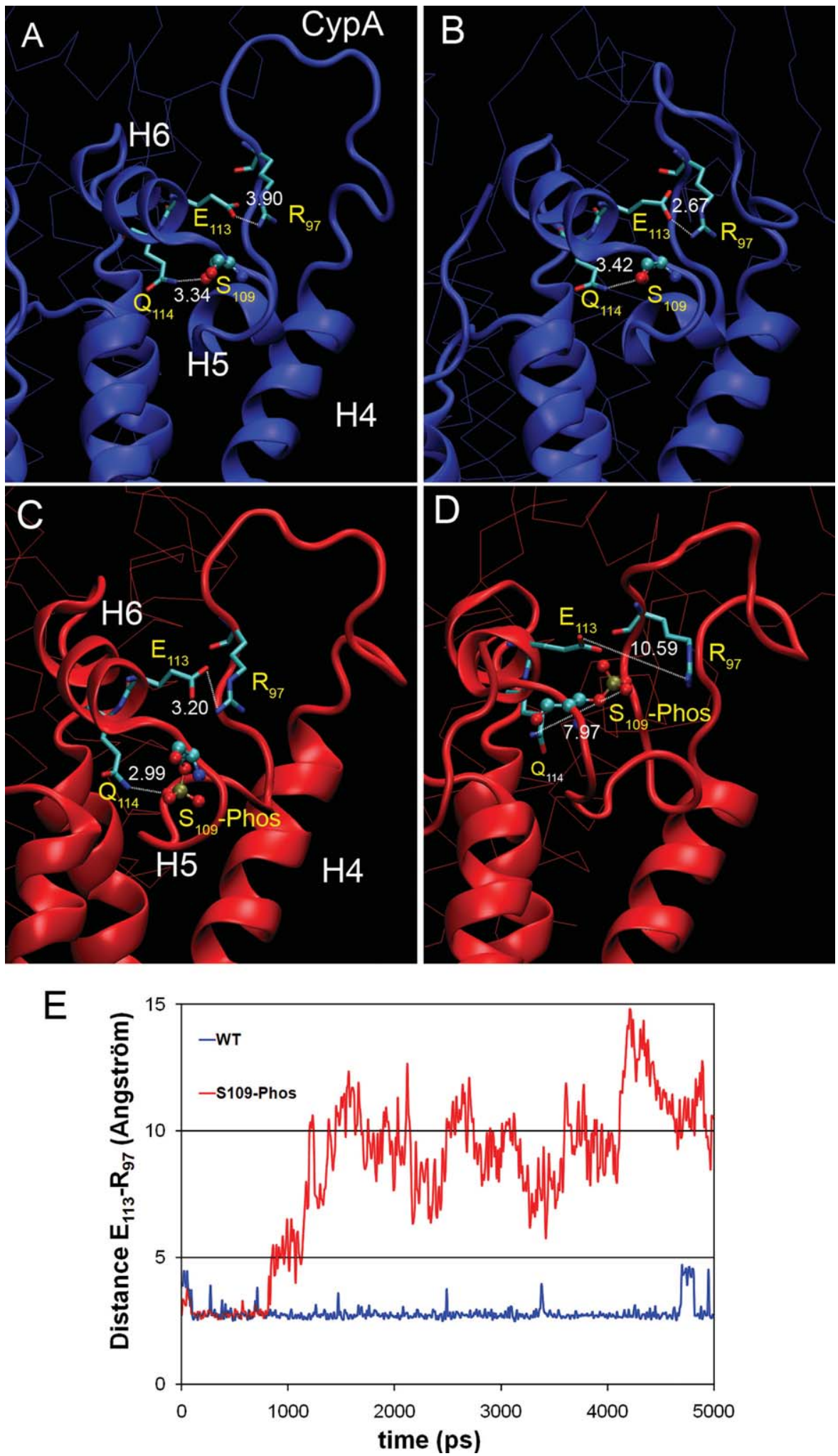

Figure 2

Stability influenced by long distance interaction with $S_{109}$ phosphorylated CA. Snapshots from molecular dynamics simulation of unphosphorylated CA (A and $\mathbf{B}$ in blue) compared to $S_{109}$ phosphorylated CA hexamer ( $\mathbf{C}$ and $\mathbf{D}$ in red) showing the changes in the interactions network upon phosphorylation of $\mathrm{S}_{109}$. Structures of CA were taken at 0 and 5 ns in both cases. "CypA" denotes the Cyclophilin A binding loop and H4, 5 and 6 the $\alpha$-helices. Residues in "stick" or "ball and stick model" are involved in the stabilization of the protein edifice. (E) Distance $(\AA)$ between residues $\mathrm{E}_{113}$ and $\mathrm{R}_{97}$ along the simulation (unphosphorylated CA in blue and $\mathrm{S}_{109}$-Phosphorylated CA in red). 


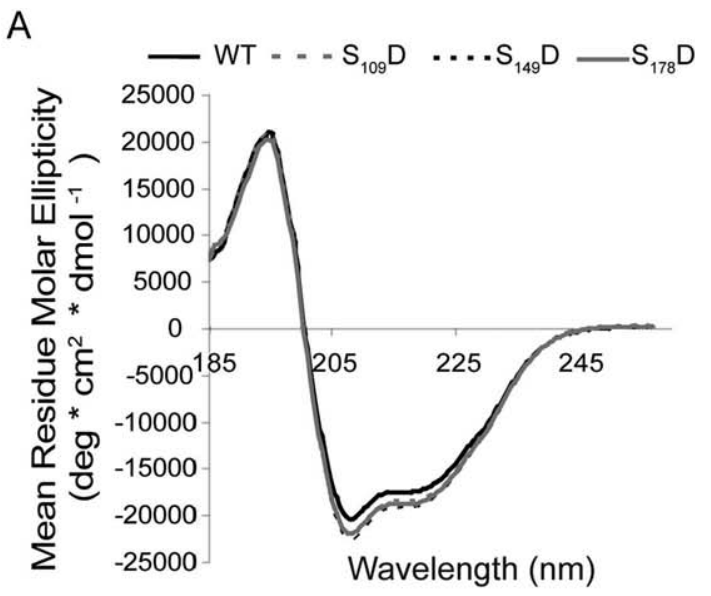

B

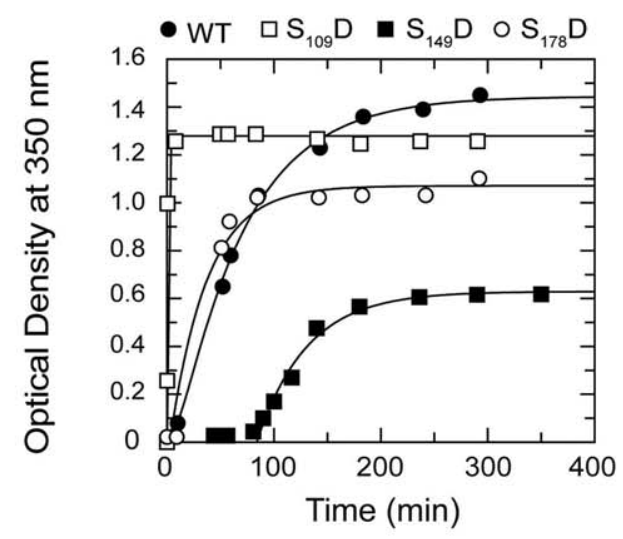

C
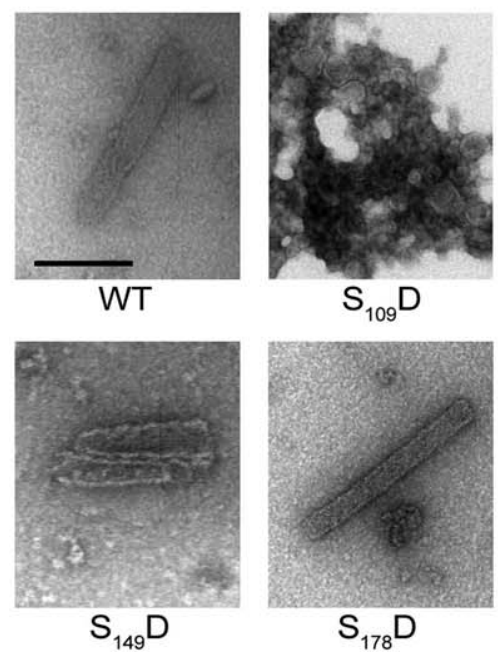

Figure 3

Impact of constitutive negative charges on in vitro assembly of bacterially expressed CA. (A) CD spectra for WT and mutant CA proteins. The raw spectra were corrected for the concentration differences and background contributed by buffer. (B) In vitro assembly kinetics of recombinant WT and mutant CA proteins at $40 \mu \mathrm{M}$. For all mutants, association rates were calculated by fitting the experimental kinetic data with a single exponential equation using the Grafit program. For $\mathrm{S}_{149} \mathrm{D}$, only the second phase of the curve was fitted to determine accurately the rate constant by using a single exponential and an offset corresponding to the lag. (C) Visualization by electron microscopy of capsomers assembled in vitro. Time of incubation is $180 \mathrm{~min}$. Identical scale was used for all images shown $($ scale bar $=100 \mathrm{~nm})$. to result in a drastic increase in kinetics of CA assembly (172-fold faster than WT). Electron microscopy of the final reaction product showed no filaments but evidenced the presence of unstructured aggregates. Therefore, the $\mathrm{S}_{109} \mathrm{D}$ mutation abolished the capacity of CA to assemble in vitro into correctly folded core-like structures. Altogether these data demonstrate that mutation of $\mathrm{S}_{109}$ into an aspartic acid is lethal for in vitro $\mathrm{CA}$ assembly, while $\mathrm{S}_{149} \mathrm{D}$ and $\mathrm{S}_{178} \mathrm{D}$ mutations have limited or no effect, respectively, and allow CA polymerization.

\section{Impact of $S_{109} D, S_{149} D$, and $S_{178}$ mutations on HIV-1 core formation and consequences for viral infectivity}

The consequences of $\mathrm{S}_{109} \mathrm{D}, \mathrm{S}_{149} \mathrm{D}$, or $\mathrm{S}_{178} \mathrm{D}$ mutations in CA were next investigated at the level of HIV-1 core assembly. Mutations were inserted into the pNL4.3 complete HIV-1 molcular clone using site-directed mutagenesis. HIV-1 viruses bearing $\mathrm{S}_{109} \mathrm{D}, \mathrm{S}_{149} \mathrm{D}$, or $\mathrm{S}_{178} \mathrm{D}$ mutations were produced by transfection of the corresponding molecular clones in 293T cells. Viral particles released in culture supernatant were quantified using a HIV-1 RT activity assay. $\mathrm{S}_{109} \mathrm{D}, \mathrm{S}_{149} \mathrm{D}$, and $\mathrm{S}_{178} \mathrm{D}$ mutations drastically decreased viral release to $<10 \%$ of that observed with WT HIV-1 although normalized according to the transfection efficiency [Fig. 4]. The impact of CA substitutions was next analyzed at the level of core morphology using electron microscopy imaging. Considering the reduced amount of viral particles produced by CA mutants, the morphological analysis was focused on concentrated envelope stripped cores. Envelope of WT and mutant viruses was removed by ultracentrifugation through a sucrose cushion overlaid with detergent, as previously reported, ${ }^{20}$ and processed for electron microscopy imaging [see Fig. 5]. Using this strategy, recognizable coneshaped structures, reminiscent of intact HIV-1 cores, were predominantly observed from $\mathrm{S}_{178} \mathrm{D}$ preparations. When $\mathrm{S}_{149} \mathrm{D}$ samples were analyzed, cores appeared heterogeneous in size and shape. Most cores displayed irregular surfaces suggesting that mutant CA does not assemble properly. Finally, there were no conical structures observed for $\mathrm{S}_{109} \mathrm{D}$ samples which appeared to be replaced by unstructured aggregates formed of CA monomers. A comprehensive analysis of virus-associated proteins using immunoblotting experiments of normalized amounts of viral particles revealed that poorly mature $\mathrm{CA}$ protein was associated to $\mathrm{S}_{109} \mathrm{D}$ viruses (data not shown). In addition, an accumulation of unprocessed Gag intermediates was detected, a pattern typical for maturation defects. On the contrary, protein expression pattern was identical for WT, $\mathrm{S}_{109} \mathrm{D}$, and $\mathrm{S}_{149} \mathrm{D}$ viruses. No additional maturation defect was observed and virusassociated CypA was detected at similar levels for WT and mutant particles (data not shown).

The assembled core plays an essential role in viral infectivity by regulating early steps of HIV-1 replicative 


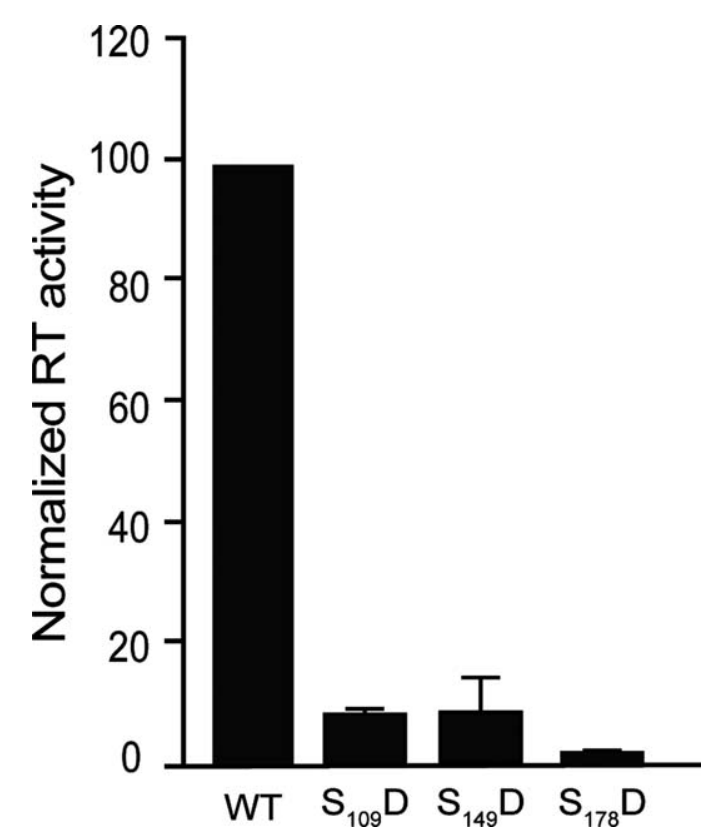

Figure 4

Viral particles production for $\mathrm{S}_{109} \mathrm{D}, \mathrm{S}_{149} \mathrm{D}$, and $\mathrm{S}_{178} \mathrm{D}$ HIV-1 mutants. Viral particle release was measured from culture supernatant of 293T cells transfected with normalized amounts of molecular HIV-1 clones encoding either wild-type (WT) or mutant CA by quantification of viral reverse transcription. Values are corrected according to transfection efficiency determined by co-transfection of a pack- $\beta$ gal vector allowing constitutive expression of $\beta$-galactosidase in the transfected cells. Values are the mean of four separate experiments and are expressed as a percentage of reverse transcription activity measured from cells transfected with wild-type HIV-1 provirus.

cycle that allow reverse transcription of HIV-1 genomic RNA into proviral DNA. ${ }^{4}$ Accordingly, the ability of WT viruses and $\mathrm{CA}$ mutant to replicate was monitored by quantification of HIV-1 LTR-driven $\beta$-galactosidase activity using the MAGIC-5B reporter cell line. ${ }^{46}$ Using normalized inputs, $\mathrm{S}_{109} \mathrm{D}, \mathrm{S}_{149} \mathrm{D}$, and $\mathrm{S}_{178} \mathrm{D}$ viruses were found to display dramatically reduced infectivity levels as compared to WT viruses [Fig. 6(A)]. Efficiency of early replicative steps was next analyzed from the same biological samples by monitoring HIV-1 DNA synthesis using qPCR amplification. As shown in Figure 6(B), each mutant tested was impaired for reverse transcription and was found unable to support early proviral DNA intermediate synthesis. Accordingly, infectivity defects observed for CA mutants are related to their incapacity to produce proviral DNA.

Altogether, our data indicate that the presence of an aspartic acid at positions 149 or 109 in CA resulted in morphologically altered cores or unstructured aggregates, respectively. For $\mathrm{S}_{109} \mathrm{D}$ viruses, such dramatic alteration may be related to an incomplete processing of Gag precursor by the viral protease as evidenced by immunoblotting experiments (data not shown). In contrast, the presence of a constitutive negative charge at positions 178 in CA does not compromise the ability of CA to assemble into correctly folded cores. Nevertheless, all mutant viruses lack infectivity, due to an impairment of proviral DNA synthesis during early steps of infection.

\section{DISCUSSION}

It has been known for many years that HIV-1 CA is a phosphoprotein. ${ }^{33,34} \mathrm{~S}_{109}, \mathrm{~S}_{149}$, and $\mathrm{S}_{178}$ residues have been identified as major phospho-acceptor sites in CA. ${ }^{37}$ The conservation of these residues is required for viral infectivity and alanine substitution at these sites abolished HIV-1 replication at the level of proviral DNA synthesis. ${ }^{38}$ According to these observations and to a number of studies indicating that negative charges can modulate HIV-1 core assembly, 5,21,30-32 the hypothesis was built that CA phosphorylation may regulate structural features of $\mathrm{HIV}-1$ core and thus impact the retroviral life cycle. However, the impact of negative charges at phospho-acceptor positions has never been investigated so far. Here, we conducted a multidisciplinary study aiming at evaluating the impact of CA phosphorylation on HIV-1 core assembly. The strategy used relies on analyzing the behavior of a homogenous population of CA proteins bearing constitutive phosphorylation or negative charges. This extreme
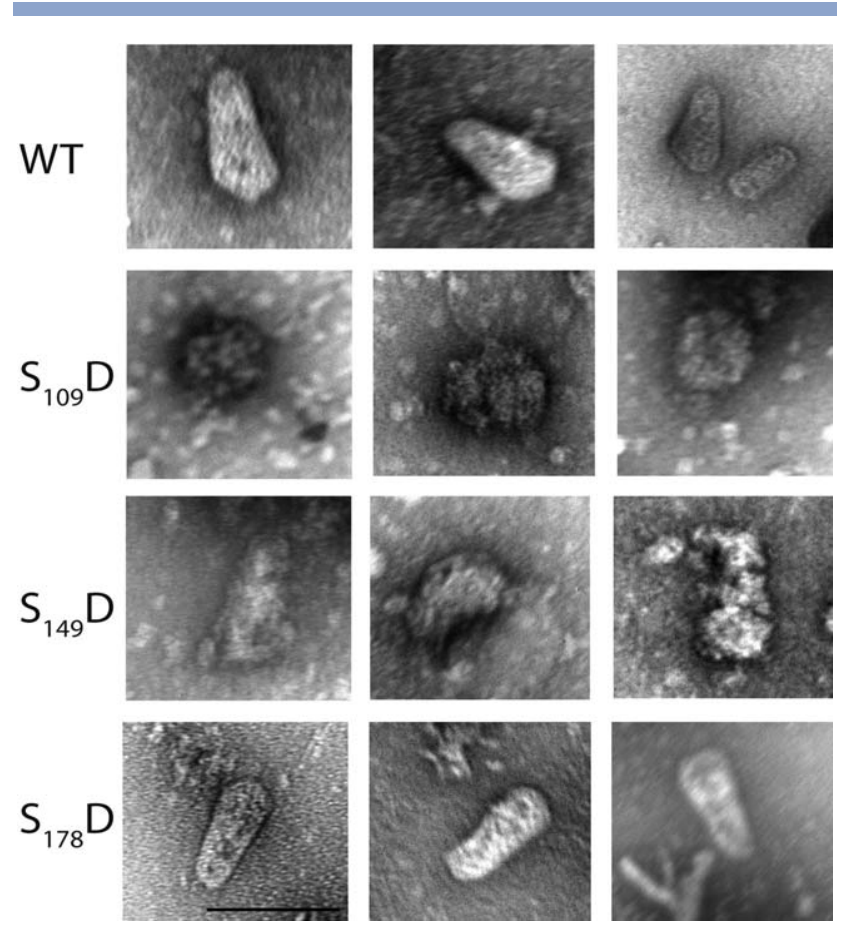

\section{Figure 5}

Analysis of WT and mutant cores morphology. 293T cells were transfected with equal amounts of WT or mutant molecular clones. Viral particles released in culture supernatant were collected, envelopestripped, stained, and processed for electron microscopy. Pictures shown are representative of observations performed on 15 cores. The scale is indicated $(100 \mathrm{~nm})$ and is identical for all images shown. 

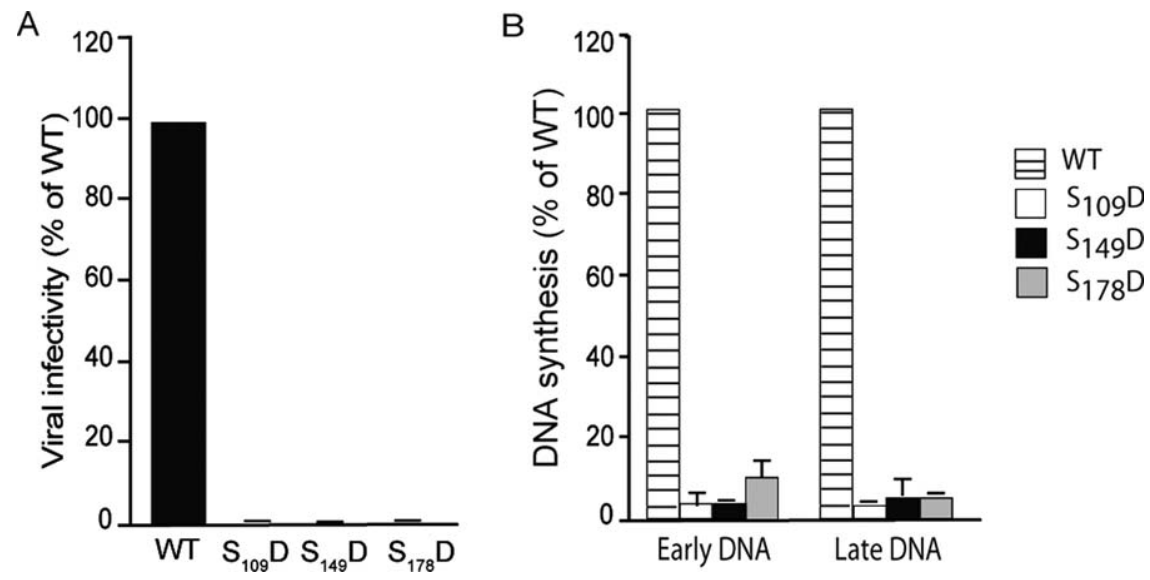

\section{Figure 6}

Phenotypic characterization of $\mathrm{S}_{109} \mathrm{D}, \mathrm{S}_{149} \mathrm{D}$, and $\mathrm{S}_{178} \mathrm{D}$ HIV-1 mutants. (A) Viral infectivity of normalized infectious doses of WT and mutant viruses was monitored using the MAGIC-5B indicator cells lines stably expressing HIV-1 receptors CD4, CXCR4, and CCR5 and a $\beta$-galactosidase gene placed under control of the HIV-1 LTR promoter. Forty-eight hours postinfection, infectivity levels were determined as cell-associated $\beta$-galactosidase activity and normalized according to total protein content of the sample. Values are the mean of four separate experiments and are expressed as a percentage of infectivity observed for wild-type HIV-1 viruses. (B) Proviral DNA synthesis was measured in MAGIC-5B infected for $24 \mathrm{~h}$ with normalized amounts of WT HIV-1 or CA mutants using a quantitative PCR approach. PCR primers allowing the detection of early or late reverse transcription intermediates have been used. For each sample copy numbers have been normalized according to GAPDH gene copies. Final values represent the mean of four separate experiments performed in triplicate and are expressed as a percentage of WT conditions. All experimental procedures are detailed in Ref. 38.

situation is indicative of whether negative electrostatic charges located at critical positions known to be phospho-acceptor sites, impact the assembling capacities of CA. The consequences of phosphorylation on CA hexamers stability and plasticity were modeled in silico. According to our results, the CTD part of CA appears highly flexible compared to the NTD. Such a high CTD flexibility agrees with previous in silico studies of CA. ${ }^{25}$ While this manuscript was submitted, three crystal structures of either hexameric mutant CA or CA fusion protein were published. ${ }^{45}$ Despite these structures built from modified CA, hexamers were found to be more compact than that reported in the present study, mainly showing a rigid core formed by N-terminal moieties and a similar flexibility for the CTD, thereby validating in part our model. Moreover, after comparing crystal and modeled structures, the interactions networks observed for phosphorylated hexamers at position $S_{109}$ or $S_{178}$ are compatible with both structures according to the distances separating the affected residues $\left(\mathrm{S}_{109}-\mathrm{Q}_{114}, \mathrm{E}_{113}-\mathrm{R}_{97}, \mathrm{~S}_{178}-\mathrm{K}_{70}\right)$. The CTD flexibility may also contribute to the ability of this region to form swapped domains with the MHR 26 and thus to stabilize the hexameric network. According to previous and recent X-ray structures of the CA monomer, dimer or hexamer, the CTD may be positioned either in the same vertical axis than that of the NTD or slightly tilted leading to different NTD-CTD interactions to occur. This structural feature may be of particular interest for drug design and also for the fine tun- ing of core assembly. In addition, these results are in good agreement with the high variability that involves a hinge motion between NTD and CTD described recently in the new CTD-CTD interface between three adjacent hexamers. ${ }^{22}$

\section{Effect of CA phosphorylation at position 109}

Analysis of the $\mathrm{S}_{109} \mathrm{D}$ substitution showed that this mutation is lethal not only for in vitro assembly but also for in vivo core formation, leading to the production of immature non infectious viral particles. Interestingly, the rate of recombinant $\mathrm{S}_{109} \mathrm{D}$ CA assembly was significantly increased in vitro. Therefore, the presence of a negative charge at position 109 may stimulate the nucleation step in an inappropriate way, leading to incorrect protein/protein interactions. Such enhanced assembly rate was previously described for other charged residues in the NTD moiety of CA. ${ }^{30}$ Molecular dynamics simulations mimicking phosphorylation at position $\mathrm{S}_{109}$ showed an increased flexibility of the NTD including $\alpha$ helices 5 and 6. This effect is exerted through the abolition of the hydrogen bond formed between $\mathrm{S}_{109}$ and $\mathrm{Q}_{114}$ and of the salt bridge formed by residues $\mathrm{R}_{97}$ and $\mathrm{E}_{113}$, both interactions being required for keeping the rigidity of the different helices that are closed to the CypA loop. However, no direct modification for CypA binding was observed in biochemical analysis of $\mathrm{S}_{109} \mathrm{D}$ HIV-1 viruses (data not shown). Previous studies based on in vitro assembly of 
recombinant $\mathrm{CA}$ demonstrated that the deletion of the CypA binding loop stimulates CA aggregation allowing the formation of organized structures. ${ }^{21}$ Here, we demonstrate that a negative charge near the CypA loop results in the production of unstructured aggregates. In vivo, $\mathrm{S}_{109} \mathrm{D}$ viruses were impaired for Gag processing. Hence, the $\mathrm{S}_{109} \mathrm{D}$ mutation is deleterious both for Gag precursor maturation and assembly of mature CA. It has to be noticed that a serine residue is conserved at the corresponding position in CA encoded by HIV-2 and simian immunodeficiency virus (SIV), suggesting that a crucial function is fulfilled by this residue in the retroviruses life cycle. Alanine substitution of the corresponding residue $\mathrm{S}_{106}$ in SIV CA results in poor particle release with completely impaired infectivity, ${ }^{47}$ a phenotype very similar to that reported herein for the $\mathrm{S}_{109} \mathrm{D}$ and previously for the $\mathrm{S}_{109} \mathrm{~A}$ HIV-1 viruses. 38 The presence of a serine residue at position 109 is thus strictly required to produce normally assembled mature viruses. Altogether, it appears that both alanine and aspartic acid substitution may result in an inappropriate conformation, damaging for maturation by the retroviral protease. Accordingly, it is clear that if the hypothesis for a transient phosphorylation of $S_{109}$ residue cannot be rejected, immature Gag and fully mature CA would require being completely dephosphorylated at position $S_{109}$ to assemble into normally folded cores. This hypothesis is reinforced by observations indicating that despite delayed for kinetics of assembly, recombinant $\mathrm{S}_{109} \mathrm{~A}$ CA assemble into normally folded tubes in vitro (Supporting Information Fig. $1)$. In the context of the assembled core, the contribution of $\mathrm{S}_{109}$ phosphorylation in promoting core disassembly may be considered if phosphorylation at this site occurs during an intracellular step of the HIV-1 life cycle.

\section{Effect of CA phosphorylation at position 149}

Recombinant CA protein bearing the $\mathrm{S}_{149} \mathrm{D}$ mutation was delayed for in vitro assembly initiation. Electron microscopy imaging showed that tubes assembled in vitro from recombinant $\mathrm{S}_{149} \mathrm{D}$ CA were mostly correctly folded despite their shorter length compared to those formed by WT CA. In vivo, the significant alterations in core morphology were depicted both from entire $S_{149} \mathrm{D}$ viral particles and from the corresponding envelope-stripped cores observed in electron microscopy imaging. Such defects may account for the lack of infectivity of the corresponding viruses that were unable to produce proviral DNA. These data support the idea that a negative charge at position 149 is detrimental for core assembly. Dynamics simulations of CA hexamers revealed that $S_{149}$ phosphorylation increases inter-monomer distances by inducing several charge repulsions within each monomer, notably with $\mathrm{D}_{152}$ (data not shown). Such repulsion may explain the destabilizing effect observed during the simu- lation and may result in vivo in impaired protein edifice assembly, deleterious for viral infectivity. This hypothesis is concordant with the location of $\mathrm{S}_{149}$ residue near the C-terminus of CA helix 7 that was found to participate in the CTD/NTD contacts that strengthen CA hexamer in the crystal structure. ${ }^{45}$ Our model is also supported by a recent NMR study demonstrating the pivotal role of amino acid residues lying in the interdomain linker for the formation of CTD dimers. ${ }^{22}$ These residues, neighboring $S_{149}$, participate in extensive hydrophobic interactions with residues located in $\alpha$-helix 9. On this basis, a negative charge at position $\mathrm{S}_{149}$ may thus have a significant impact on CTD dimerization and as a consequence, on the stability of the assembled CA hexamer network.

\section{Effect of CA phosphorylation at position 178}

Here, we found that the addition of a phosphate group to residue $S_{178}$ significantly stabilized the structure of the CA hexamer in silico. Interestingly, truncation of interfacial side chain at position 178 was previously found to increase the affinity of isolated CTD domains of CA, indicating that the amino-acid at this position may be involved in electrostatic repulsion events required for a functional HIV-1 core structure. ${ }^{32}$ Additional observations suggested the role of charged residues in both domains of $\mathrm{CA}$ (e.g., $\mathrm{E}_{45} \mathrm{~A}$ and $\mathrm{E}_{128} \mathrm{~A} / \mathrm{R}_{132} \mathrm{~A}$ ) in stabilizing the HIV-1 core and infectivity. ${ }^{4}$ Accordingly, the existence of a balance of favorable and unfavorable interactions has been suggested to regulate the capacity of CA to assemble into core structures or to disassemble during viral uncoating. When evaluated in vitro, the $\mathrm{S}_{178} \mathrm{D} C \mathrm{CA}$ protein assembled into core-like structures that are very similar in morphology to that produced by wild-type CA. Moreover, cores formed by $\mathrm{S}_{178} \mathrm{D} H \mathrm{HV}-1$ virions in vivo were correctly folded. Therefore, the presence of a negative charge at this site, despite lying within an assembly-sensitive surface, does not apparently interfere with the formation of the CA network. Nevertheless, $\mathrm{S}_{178} \mathrm{D}$ HIV-1 mutant viruses were unable to replicate and were impaired during the early steps of infection (reverse transcription). It is thus conceivable that the presence of a negative charge at position 178 is reasonably well tolerated at the assembly level but not for an intracellular step of HIV-1 replication. We previously reported that a $S_{178} A$ mutation reduces HIV-1 core stability and also results in poor infectivity. ${ }^{38}$ From our simulation study, mimicking $\mathrm{S}_{178}$ phosphorylation resulted in sort of "freezing" of the CA hexamer. Such stabilization was explained by additional salt bridges observed during the simulation which could reinforce the structural stability of the hexamer/core. With the crystal structures similar hypothesis can be drawn with the potential inter-monomer interaction between $K_{70}$ and $S_{178}$ (even $K_{70}$ already interacts with $\mathrm{E}_{180}$ ). Hence, phosphorylation of residue $S_{178}$, in stabiliz- 
ing the structure of CA hexamers, could modify the hexameric network to a higher order and thus regulate the rigidity of the assembled core, thereby modulating its uncoating capacity once injected in the cell cytoplasm. Alternatively, the lack of flexibility may decrease the ability of the core to interact with a cellular factor required for core disassembly and release of the viral genome.

In conclusion, our results argue for the contribution of phosphorylation in regulating the appropriate structure and stability of the viral core that allow HIV-1 to be infectious. Together with our previous observations, ${ }^{37}$ our data clearly indicate that the presence of serine residues that can be phosphorylated in HIV-1 CA is crucial for virus replication and in some cases for regulating the assembly/ disassembly process. Based on the phenotypes observed for $S \rightarrow D$ mutants and on the modeling study of phosphorylated CA, we propose here that phosphorylation at position 109 or 149 reduces the assembling capacity of mature CA. For $\mathrm{S}_{109}$ phosphorylation, an additional effect was observed at the level of Gag precursor maturation and its possible consequences on Gag accessibility to the viral protease need to be questioned. On the other hand, phosphorylation of $S_{178}$ may increase the stability of the viral core by reducing the plasticity of the assembled CA network. In either case, phosphorylation at these sites, if it occurs in the context of the assembled core, can be considered as an event interfering with core dissociation and release of HIV-1 DNA during early replicative steps.

We previously reported that viruses that encode hypophosphorylated CA also display replication defects, related to impaired core assembly and stabilization. ${ }^{38}$ In the physiological context, the extent to which CA is phosphorylated remains unknown. Former 2D-gels studies reported that only a subset of CA present in the HIV-1 particle may become phosphorylated. ${ }^{33,34}$ Accordingly, not all CA proteins forming the core network become phosphorylated at the same time. Data reported here have been obtained mimicking an extreme situation in which each CA molecule participating in the hexamer would become constitutively phosphorylated. In the light of our results several hypothesis can be built to model the physiological impact of negative charges in CA. A reasonable hypothesis could be that, in the physiological context, phosphorylation could occur locally, resulting in the modification of all CA molecules located in a restricted area of the viral core. Alternatively, a limited number of events within each CA hexamer may occur. Choosing between these two hypothesis remains elusive to date, but our data support that in both cases, phosphorylation may have a drastic impact on the local organization of CA within the hexamer and on the global organization of the hexamer network within the assembled core. However, the complexity of phenotypes observed here and previously 38 supports the idea that phosphorylation of CA is dynamic, a situation that would allow efficient assembly and enhance the disassembly of the HIV-1 core at the appropriate points in the replication cycle. In light of these observations, analyzing the dynamics of CA phosphorylation during Gag processing, assembly of mature CA and early postfusion steps may provide a crucial insight into assembly/disassembly mechanisms.

\section{ACKNOWLEDGMENTS}

We thank S. Campagna (Structural Biology Platform, CBS, Montpellier) for CD facilities and T. Barman for corrections of the English. This work was performed using HPC resources from GENCI-CINES. SB is a fellow of the CNRS-Région Languedoc Roussillon.

\section{REFERENCES}

1. Wilk T, Gross I, Gowen BE, Rutten T, de Haas F, Welker R, Krausslich HG, Boulanger P, Fuller SD. Organization of immature human immunodeficiency virus type 1. J Virol 2001;75:759-771.

2. Briggs JA, Wilk T, Welker R, Krausslich HG, Fuller SD. Structural organization of authentic, mature HIV-1 virions and cores. Embo J 2003;22:1707-1715.

3. Leschonsky B, Ludwig C, Bieler K, Wagner R. Capsid stability and replication of human immunodeficiency virus type 1 are influenced critically by charge and size of Gag residue 183. J Gen Virol 2007;88(Pt 1):207-216.

4. Forshey BM, von Schwedler U, Sundquist WI, Aiken C. Formation of a human immunodeficiency virus type 1 core of optimal stability is crucial for viral replication. J Virol 2002;76:5667-5677.

5. von Schwedler UK, Stray KM, Garrus JE, Sundquist WI. Functional surfaces of the human immunodeficiency virus type 1 capsid protein. J Virol 2003;77:5439-5450.

6. Dismuke DJ, Aiken C. Evidence for a functional link between uncoating of the human immunodeficiency virus type 1 core and nuclear import of the viral preintegration complex. J Virol 2006;80:3712-3720.

7. Dorfman T, Bukovsky A, Ohagen A, Hoglund S, Gottlinger HG. Functional domains of the capsid protein of human immunodeficiency virus type 1. J Virol 1994;68:8180-8187.

8. Borsetti A, Ohagen A, Gottlinger HG. The C-terminal half of the human immunodeficiency virus type 1 gag precursor is sufficient for efficient particle assembly. J Virol 1998;72:9313-9317.

9. Krausslich HG, Facke M, Heuser AM, Konvalinka J, Zentgraf H. The spacer peptide between human immunodeficiency virus capsid and nucleocapsid proteins is essential for ordered assembly and viral infectivity. J Virol 1995;69:3407-3419.

10. Worthylake DK, Wang H, Yoo S, Sundquist WI, Hill CP. Structures of the HIV-1 capsid protein dimerization domain at $2.6 \AA$ resolution. Acta Crystallogr D Biol Crystallogr 1999;55(Pt 1):85-92.

11. Gamble TR, Vajdos FF, Yoo S, Worthylake DK, Houseweart M, Sundquist WI, Hill CP. Crystal structure of human cyclophilin A bound to the amino-terminal domain of HIV-1 capsid. Cell 1996;87:1285-1294.

12. Gitti RK, Lee BM, Walker J, Summers MF, Yoo S, Sundquist WI. Structure of the amino-terminal core domain of the HIV-1 capsid protein. Science 1996;273:231-235.

13. von Schwedler UK, Stemmler TL, Klishko VY, Li S, Albertine KH, Davis DR, Sundquist WI. Proteolytic refolding of the HIV-1 capsid protein amino-terminus facilitates viral core assembly. EMBO J 1998;17:1555-1568.

14. Franke EK, Yuan HE, Luban J. Specific incorporation of cyclophilin A into HIV-1 virions. Nature 1994;372:359-362.

15. Gamble TR, Yoo S, Vajdos FF, von Schwedler UK, Worthylake DK, Wang H, McCutcheon JP, Sundquist WI, Hill CP. Structure of the carboxyl-terminal dimerization domain of the HIV-1 capsid protein. Science 1997;278:849-853.

16. Ganser BK, Li S, Klishko VY, Finch JT, Sundquist WI. Assembly and analysis of conical models for the HIV-1 core. Science 1999;283:80-83. 
17. Li S, Hill CP, Sundquist WI, Finch JT. Image reconstructions of helical assemblies of the HIV-1 CA protein. Nature 2000;407:409-413.

18. Gross I, Hohenberg H, Krausslich HG. In vitro assembly properties of purified bacterially expressed capsid proteins of human immunodeficiency virus. Eur J Biochem 1997;249:592-600.

19. Gross I, Hohenberg H, Huckhagel C, Krausslich HG. N-Terminal extension of human immunodeficiency virus capsid protein converts the in vitro assembly phenotype from tubular to spherical particles. J Virol 1998;72:4798-4810.

20. Ehrlich LS, Agresta BE, Carter CA. Assembly of recombinant human immunodeficiency virus type 1 capsid protein in vitro. J Virol 1992;66:4874-4883.

21. Ganser-Pornillos BK, von Schwedler UK, Stray KM, Aiken C, Sundquist WI. Assembly properties of the human immunodeficiency virus type 1 CA protein. J Virol 2004;78:2545-2552.

22. Byeon IJ, Meng X, Jung J, Zhao G, Yang R, Ahn J, Shi J, Concel J, Aiken C, Zhang P, Gronenborn AM. Structural convergence between Cryo-EM and NMR reveals intersubunit interactions critical for HIV-1 capsid function. Cell 2009;139:780-790.

23. Ganser-Pornillos BK, Cheng A, Yeager M. Structure of full-length HIV-1 CA: a model for the mature capsid lattice. Cell 2007;131:70-79.

24. Berthet-Colominas C, Monaco S, Novelli A, Sibai G, Mallet F, Cusack S. Head-to-tail dimers and interdomain flexibility revealed by the crystal structure of HIV-1 capsid protein (p24) complexed with a monoclonal antibody Fab. Embo J 1999;18:1124-1136.

25. Alcaraz LA, Del Alamo M, Mateu MG, Neira JL. Structural mobility of the monomeric C-terminal domain of the HIV-1 capsid protein. Febs J 2008;275:3299-3311.

26. Ivanov D, Tsodikov OV, Kasanov J, Ellenberger T, Wagner G, Collins T. Domain-swapped dimerization of the HIV-1 capsid C-terminal domain. Proc Natl Acad Sci USA 2007;104:4353-4358.

27. Lu B, Stubbs G, Culver JN. Carboxylate interactions involved in the disassembly of tobacco mosaic tobamovirus. Virology 1996;225:11-20.

28. Ellard FM, Drew J, Blakemore WE, Stuart DI, King AM. Evidence for the role of His-142 of protein 1C in the acid-induced disassembly of foot-and-mouth disease virus capsids. J Gen Virol 1999;80(Pt 8): 1911-1918.

29. Cheslock SR, Poon DT, Fu W, Rhodes TD, Henderson LE, Nagashima $\mathrm{K}$, McGrath CF, Hu WS. Charged assembly helix motif in murine leukemia virus capsid: an important region for virus assembly and particle size determination. J Virol 2003;77:7058-7066.

30. Douglas CC, Thomas D, Lanman J, Prevelige PE, Jr. Investigation of N-terminal domain charged residues on the assembly and stability of HIV-1 CA. Biochemistry 2004;43:10435-10441.

31. del Alamo M, Mateu MG. Electrostatic repulsion, compensatory mutations, and long-range non-additive effects at the dimerization interface of the HIV capsid protein. J Mol Biol 2005;345:893-906.

32. del Alamo M, Neira JL, Mateu MG. Thermodynamic dissection of a low affinity protein-protein interface involved in human immunodeficiency virus assembly. J Biol Chem 2003;278:27923-27929.

33. Mervis RJ, Ahmad N, Lillehoj EP, Raum MG, Salazar FHR, Chan HW, Venkatesan S. The gag gene products of human immunodeficiency virus type 1: alignment within the gag open reading frame, identification of post-transcriptional modifications and evidence for alternative gag precursors. J Virol 1988;62:3993-4002.

34. Veronese FM, Copeland TD, Oroszlan S, Gallo RC, Sarngaharan MG. Biochemical and immunological analysis of human immunodeficiency virus gag gene products p17 and p24. J Virol 1988;62:795-801.

35. Cartier C, Hemonnot B, Gay B, Bardy M, Sanchiz C, Devaux C, Briant L. Active cAMP-dependent protein kinase incorporated within highly purified HIV-1 particles is required for viral infectivity and interacts with viral capsid protein. J Biol Chem 2003;278:3521135219.

36. Cartier C, Deckert M, Grangeasse C, Trauger R, Jensen F, Bernard A, Cozzone A, Desgranges C, Boyer V. Association of ERK2 mitogen-activated protein kinase with human immunodeficiency virus particles. J Virol 1997;71:4832-4837.

37. Cartier C, Sivard P, Tranchat C, Decimo D, Desgranges C, Boyer V. Identification of three major phosphorylation sites within HIV-1 capsid. Role of phosphorylation during the early steps of infection. J Biol Chem 1999;274:19434-19440.

38. Brun S, Solignat M, Gay B, Bernard E, Chaloin L, Fenard D, Devaux C, Chazal N, Briant L. VSV-G pseudotyping rescues HIV-1 CA mutations that impair core assembly or stability. Retrovirology 2008;5:57. PMID: 18605989.

39. Phillips JC, Braun R, Wang W, Gumbart J, Tajkhorshid E, Villa E, Chipot C, Skeel RD, Kale L, Schulten K. Scalable molecular dynamics with NAMD. J Comput Chem 2005;26:1781-1802.

40. Foloppe N, MacKerrel ADJ. All-atom empirical force field for nucleic acids: I. Parameter optimization based on small molecule and condensed phase macromolecular target data. J Comput Chem 2000;21:86-104.

41. Jorgensen WL, Chandrasekhar J, Madura JD, Impey RW, Klein ML. Comparison of simple potential functions for simulating liquid water. J Chem Phys 1983;79:926-935.

42. Nose S, Klein ML. Constant-temperature-constant-pressure molecular-dynamics calculations for molecular solids: application to solid nitrogen at high pressure. Phys Rev B Condens Matter 1986;33: 339-342.

43. Hoover WG. Canonical dynamics: equilibrium phase-space distributions. Phys Rev A 1985;31:1695-1697.

44. Humphrey W, Dalke A, Schulten K. VMD: visual molecular dynamics. J Mol Graph 1996;14:33-38, 27-38.

45. Pornillos O, Ganser-Pornillos BK, Kelly BN, Hua Y, Whitby FG, Stout CD, Sundquist WI, Hill CP, Yeager M. X-ray structures of the hexameric building block of the HIV capsid. Cell 2009;137:12821292.

46. Hachiya A, Aizawa-Matsuoka S, Tanaka M, Takahashi Y, Ida S, Gatanaga H, Hirabayashi Y, Kojima A, Tatsumi M, Oka S. Rapid and simple phenotypic assay for drug susceptibility of human immunodeficiency virus type 1 using CCR5-expressing HeLa/CD4(+) cell clone 1-10 (MAGIC-5). Antimicrob Agents Chemother 2001;45: 495-501.

47. Rue SM, Roos JW, Clements JE, Barber SA. Conserved serines in simian immunodeficiency virus capsid are required for virus budding. Virology 2005;336:37-50. 